\title{
Analysed statistically Modelling and Optimization of Laser Machining by Response Surface Methodology
}

\author{
Hani Mizhir ${ }^{1}$, Kamil Jawad ${ }^{1}$, Zuhair H Obaid ${ }^{1}$ \\ ${ }^{1}$ Al-Furat Al-Awsat Technical University, Iraq
}

\begin{abstract}
One of the important goals of this research is to predict a relationship between the process input parameters and resultants from surface roughness features through developing a laser cutting model. In most engineering applications, natural sciences and computing; statistical methods, which are one of mathematical branch are widely used for investigating the results. Laser cutting process of stainless steel (2205) is a machining process selected for this study. The technique which adopted here is a response surface methodology (RSM). The main portion for this study is the influence of cutting speed on surface quality. To study the model response, and for statistical approach with further prediction; a mathematical based model has been developed through regression analysis. It's found that as one of the important results in this research, that cutting speed and surface roughness has a significant rule on the model response. To produce a good surface roughness, it's approved that the high cutting speed connected with high power regardless of high pressure has a high influence on surface quality.
\end{abstract}

\section{Introduction}

The emergence of advanced engineering material, complex design, sophisticated shape and unusual size of work material make more restriction for using the conventional machine in industry. Advance machining process (AMPs) is become urgent in manufacturing process as unconventional method (Choudhury and Shirley, 2010). One of the important (AMPs) is a laser machining which used to cut different types of material economically. Comparing with other types of conventional method; laser beam machining gives good properties to the final product like a fine surface (Choudhury and Shirley, 2010). In many industrial applications, and especially for purpose of cutting the hard materials, laser machining is one of the commonly method which used due to its advantages comparing with other methods (Eltawahni et al., 2012). Laser cutting process involves highly localized heat input to the work peace, no tool wear, remove less material, and minimize distortion.

It's well suited for many manufacturing process because it's highly automated, thermal and non- contact process. This method is always used to produce high surface finish products, especially in mass production with high dimensional accuracy (Madic et al., 2012). During any manufacturing process, like laser cutting, the majority of metals have resistance to the maximum operation temperature due to their structure and boundary layers (Samant and Dahotre.2009). Cutting process can be defined as a method to produce a specific geometry with some specifications by removing the material using different types of tools. The waste or access material and the finished part is the net results of any cutting process. There are different types of manufacturing process, some of these can called machining and others can be classified as cutting process, and others are coating or burning. Oxy-fuel cutting torch can be called as burning. Others process like use of chemical masking or etching to remove the excess material is called chemical process (Tulasiramarao et al., 2013).

Advance machining process (AMPs) like electron beam machine, laser beam machine, ion beam machining, plasma beam machining, ultra sonic machining (USM), chemical blanking, photo chemical machining and others are wildly used nowadays in manufacturing process (Dubey and Yadava 2008; Samant and Dahotra, 2009). Some metals like stainless steel cannot or very difficult to cut or machine by classical methods due to high melting point and low viscosity of the formed oxide; so laser cutting method is the most suitable method in this case ( Ghany and Newish, 2005).

\section{Initial Designs}

RSM is a collection of Mathematical and statistical techniques that are useful for modelling and analysis in application will be developed to investigate the selected parameters effect on the responses represented by surface roughness, and will be used to predict the surface roughness.. The response will be predicted by statistical means that refer to an empirical method to describe the relationship between the parameters and their effect on the response. RSM To establish the surface roughness 
prediction model, MINITAB 16 statistical software package will be used. Based on these runs with the particular parametric values, the experiment will be performed and the surface roughness values taken were re-entered into the matrix. After entering the surface roughness values in the modelling matrix, which will be developed by the central composite design CCD method, a complete analysis can be executed using RSM to define the importance of each parameter of the response.

\section{Practical Laser Cutting Type Materials}

The duplex stainless steel (DSS), is a mixed microstructure of about equal proportions of austenite and ferrite. The early grades were alloys of chromium, nickel and molybdenum. Therefore, Duplex stainless steel the product description (AK) steel 2205 is a ferriticaustenitic. It provides a valuable combination of high strength, excellent corrosion resistance and stresscorrosion cracking resistance as well as very good pitting resistance. In addition, it is highly resistant to stress and provides a low level of thermal expansion. Stainless steel duplex 2205 will be used in the research experiments. The initial dimensions of the work piece where; length of $2000 \mathrm{~mm}$, width of $500 \mathrm{~mm}$, thickness of $8.0 \mathrm{~mm}$ and Non-Linear incline cutting of $32^{\circ}$ for cut nozzle

\section{Cutting Parameters}

Cutting speed, laser power and gas pressure are the main parameters are studied . in addition; to find a statistical representation of the parameter to the responses, the effect of these parameters on the surface roughness are the major aspect of this study.. the high and low values of the input parameters in experiment should be identified. the high and low values are depends on the material used. in general, the range of the parameter's values are shown in table 1 . the other parameters will kept at a constant values through the experiment as shown in table 2 .

Table 1. Parameters Range.

\begin{tabular}{|l|llc|}
\hline Paramètre & \multicolumn{3}{|l|}{ Range (Low- High) } \\
\hline $\begin{array}{l}\text { Laser Power } \\
\text { (watt) }\end{array}$ & 1250 & - & 2500 \\
\hline $\begin{array}{l}\text { Cutting Speed } \\
\text { (mm/min) }\end{array}$ & 500 & - & 1000 \\
\hline Gas Pressure bar & $100 \quad-$ & 175 \\
\hline
\end{tabular}

Table 2. Parameters values during the central composite design.

\begin{tabular}{|l|l|l|}
\hline \multicolumn{3}{|c|}{ Central Composite Design } \\
\hline Factors: & 3 & Replicates: $\quad 1$ \\
\hline Base runs: & 20 & Total runs: $\quad 20$ \\
\hline Base blocks: & 1 & Total blocks: $\quad 1$ \\
\hline \multicolumn{2}{|c|}{ Two-level factorial: Full factorial } \\
\hline Cube points: & 8 \\
\hline Centre points in cube: & 6 \\
\hline Axial points: & 6 \\
\hline Centre points in axial: & 0 \\
\hline Alpha: 1.68179 & \\
\hline & \\
\hline
\end{tabular}

\begin{tabular}{|l|l|l|l|l|l|l|}
\hline $\begin{array}{c}\text { Std } \\
\text { Ord } \\
\text { er }\end{array}$ & $\begin{array}{c}\text { Run } \\
\text { Order }\end{array}$ & $\begin{array}{c}\text { Pt } \\
\text { Type }\end{array}$ & Blocks & Power & Speed & $\begin{array}{c}\text { Press } \\
\text { ure }\end{array}$ \\
\hline 1 & 1 & 1 & 1 & 1503 & 601 & 115 \\
\hline 14 & 2 & -1 & 1 & 1875 & 750 & 175 \\
\hline 2 & 3 & 1 & 1 & 2246. & 601 & 115 \\
\hline 5 & 4 & 1 & 1 & 1503. & 601 & 159 \\
\hline 11 & 5 & -1 & 1 & 1875 & 500 & 137 \\
\hline 10 & 6 & -1 & 1 & 2500 & 750 & 137 \\
\hline 15 & 7 & 0 & 1 & 1875 & 750 & 137 \\
\hline 6 & 8 & 1 & 1 & 2246 & 601 & 159 \\
\hline 3 & 9 & 1 & 1 & 1503 & 898 & 115 \\
\hline 17 & 10 & 0 & 1 & 1875 & 750 & 137 \\
\hline 12 & 11 & -1 & 1 & 1875 & 1000 & 137 \\
\hline 4 & 12 & 1 & 1 & 2246 & 898 & 115 \\
\hline 9 & 13 & -1 & 1 & 1250 & 750 & 137 \\
\hline 20 & 14 & 0 & 1 & 1875 & 750 & 137 \\
\hline
\end{tabular}

The various values within the range of specified parameters, are shown in Table 1, above and Table 2, down. After generation of the parameter values as in Table 2, it will be the data input which used into the Minitab 16 software, then a DOE model will be automatically generated with a particular run number coupled with specific parametric settings. In this research, 20 runs were generated as shown in Table 2. DOE have been applied by many authors to define the factors effect of a specified process with many outputs and to develop the mathematical relationship in order to define the optimal conditions (Eltawahni et al., 2011). Design Table 3 (randomized):

Table 3. Experimental Layout for Response.

\begin{tabular}{|c|c|c|c|c|}
\hline Run & Blk & \multicolumn{1}{|c|}{ A } & B & C \\
\hline 1 & 1 & -1.00000 & -1.00000 & -1.00000 \\
\hline 2 & 1 & 0.00000 & 0.00000 & 1.68179 \\
\hline 3 & 1 & 1.00000 & -1.00000 & -1.00000 \\
\hline 4 & 1 & -1.00000 & -1.00000 & 1.00000 \\
\hline 5 & 1 & 0.00000 & -1.68179 & 0.00000 \\
\hline 6 & 1 & 1.68179 & 0.00000 & 0.00000 \\
\hline 7 & 1 & 0.00000 & 0.00000 & 0.00000 \\
\hline 8 & 1 & 1.00000 & -1.00000 & 1.00000 \\
\hline 9 & 1 & -1.00000 & 1.00000 & -1.00000 \\
\hline 10 & 1 & 0.00000 & 0.00000 & 0.00000 \\
\hline 11 & 1 & 0.00000 & 1.68179 & 0.00000 \\
\hline 12 & 1 & 1.00000 & 1.00000 & -1.00000 \\
\hline 13 & 1 & -1.68179 & 0.00000 & 0.00000 \\
\hline 14 & 1 & 0.00000 & 0.00000 & 0.00000 \\
\hline 15 & 1 & 1.00000 & 1.00000 & 1.00000 \\
\hline
\end{tabular}

The experiment is achieved based on the runs given with the specific parametric values, then re- entering all the surface roughness values into the matrix. A complete analysis can be performed after entering the surface roughness values by using RSM to define each parameter effect on the response. . A laser cutting machine LVD Model 2513 with a maximum output power of 4000 Watt, $10.6 \mu \mathrm{m}$ wavelength and $100 \mu \mathrm{s}-$ us pulse duration will be used to conduct the $\mathrm{CO} 2$ laser cutting experiments with the nitrogen gas assistance instead of acetylene oxygen. The nitrogen can ensure the metal surface safety and maintain the metal physical characteristics. CO2 laser cutting will be used in cutting the stainless steel. Figure 
(1), Figure (2) and Figure (3); are shown the laser cutting machine, design material and control operating system..

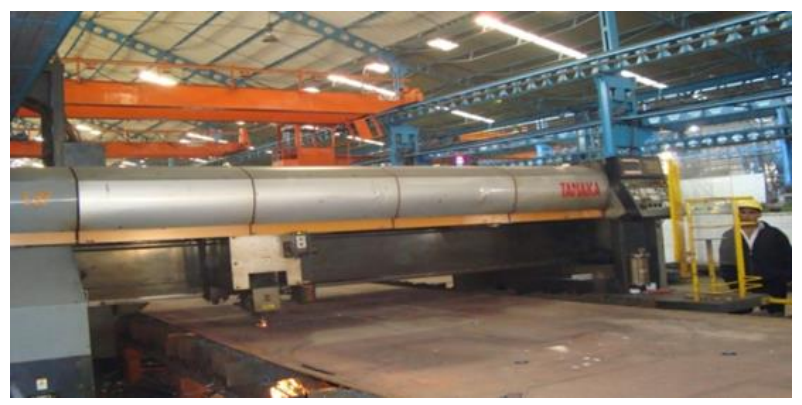

Figure 1. Cutting speed machine $\mathrm{CNC}$ laser.

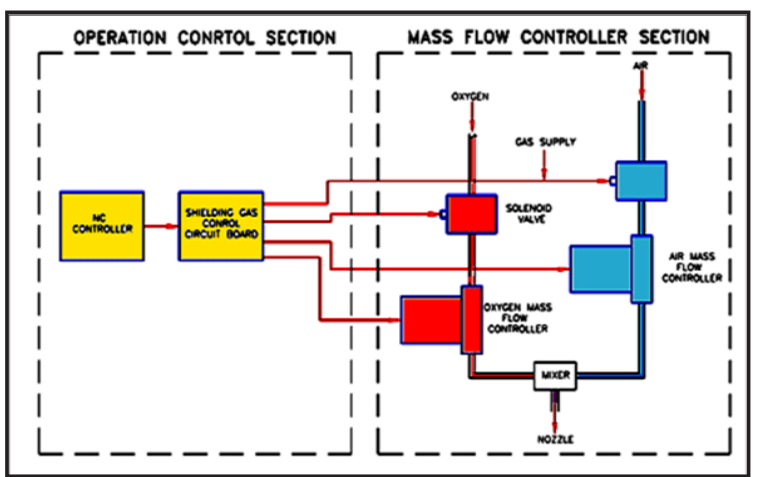

Figure 2. Operation control section and mass flow controller.

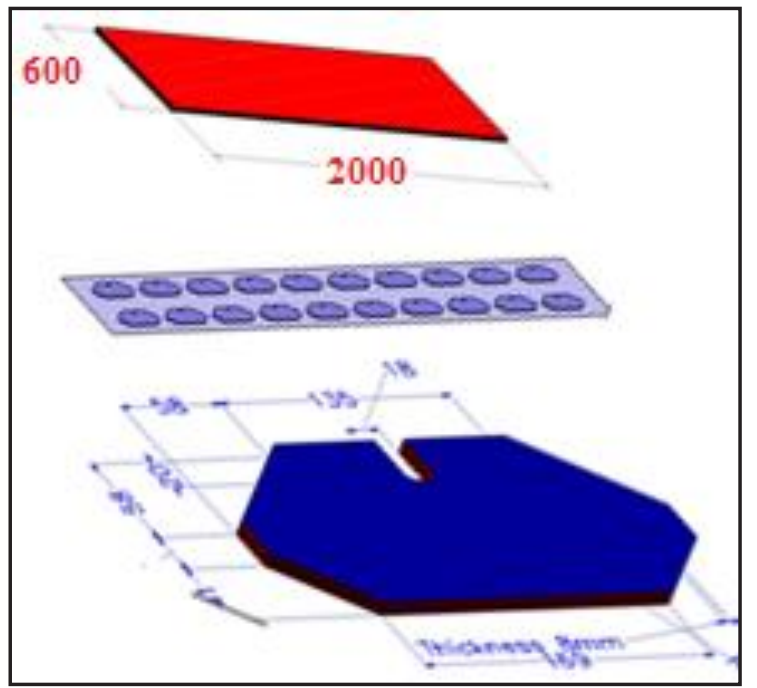

Figure 3. Dimension of plate cut by laser cutting.

\section{5: Result \& Discussion}

\subsection{Response Surface Regression}

Twenty experimental runs were carried out as listed in Table 4, Table 5, and Table 6, are show the relation between Roughness versus Pressure, Power, and Speed. The surface roughness of the developed stainless steel cutting in each experimental run was analysed by using instrument inspection and the surface roughness data were obtained. Three surface roughness measurements were collected per each sample and the average roughness were calculated. The output response of the process as tabulated in Table 4, Table 5, and Table 6. ; Experimental Results for Laser Process surface roughness Non-Linear Incline Cutting and Reading Measured
Specified in Three cutting Area x1, x2, and x 3 at Bevel Angle $32^{\circ}$ are plotted in figure 4 .

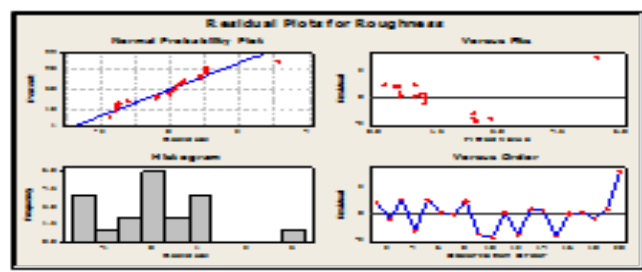

Figure.4. Residual Plots for Roughness.

Table 4. Experimental results for the area $\mathrm{x} 1 \mathrm{x} 2, \mathrm{x} 3$

\begin{tabular}{|l|l|l|l|l|}
\hline Run & $\begin{array}{c}\mathbf{X}_{\mathbf{1}} \\
\mathbf{m m}\end{array}$ & $\begin{array}{c}\mathbf{X}_{\mathbf{2}} \\
\mathbf{m m}\end{array}$ & $\begin{array}{c}\mathbf{X}_{\mathbf{3}} \\
\mathbf{m m}\end{array}$ & $\begin{array}{c}\text { Average } \\
\mathbf{m m}\end{array}$ \\
\hline 1 & 0.93 & 1.31 & 1.75 & 1.34 \\
\hline 2 & 0.88 & 0.75 & 0.76 & 0.79 \\
\hline 3 & 2.19 & 1.92 & 1.85 & 1.98 \\
\hline 4 & 1.22 & 1.17 & 1.16 & 1.18 \\
\hline 5 & 1.18 & 1.21 & 1.33 & 1.24 \\
\hline 6 & 0.80 & 0.75 & 0.65 & 0.75 \\
\hline 7 & 1.00 & 1.18 & 1.39 & 1.19 \\
\hline 8 & 1.35 & 1.40 & 1.62 & 1.46 \\
\hline 9 & 1.54 & 1.13 & 1.11 & 1.26 \\
\hline 10 & 0.71 & 0.64 & 0.69 & 0.69 \\
\hline 11 & 1.25 & 1.27 & 1.31 & 1.28 \\
\hline 12 & 0.94 & 0.73 & 0.84 & 0.84 \\
\hline 13 & 1.42 & 0.80 & 0.59 & 0.94 \\
\hline 14 & 1.84 & 1.15 & 0.92 & 1.30 \\
\hline 15 & 1.54 & 1.25 & 0.81 & 1.20 \\
\hline
\end{tabular}

Table 5. Experimental run and results of surface Roughness

\begin{tabular}{|l|l|l|l|l|l|l|l|l|}
\hline Run & $\begin{array}{c}\text { Std } \\
\text { Ord } \\
\text { er }\end{array}$ & $\begin{array}{c}\text { Run } \\
\text { Ord } \\
\text { er }\end{array}$ & $\begin{array}{c}\text { Pt } \\
\text { Ty } \\
\text { pe }\end{array}$ & $\begin{array}{l}\text { BI } \\
\text { oc } \\
\text { ks }\end{array}$ & power & $\begin{array}{l}\text { spee } \\
\text { d }\end{array}$ & $\begin{array}{c}\text { press } \\
\text { ure }\end{array}$ & $\begin{array}{c}\text { Rough } \\
\text { ness }\end{array}$ \\
\hline \hline 2 & 7 & 2 & 1 & 1 & 1503 & 898. & 5.1 & 0.79 \\
\hline 3 & 19 & 3 & 0 & 1 & 1875. & 750. & 4. & 1.98 \\
\hline 4 & 14 & 4 & -1 & 1 & 1875 & 750 & 6 & 1.18 \\
\hline 5 & 3 & 5 & 1 & 1 & 1503. & 898 & 2. & 1.24 \\
\hline 6 & 4 & 6 & 1 & 1 & 2246. & 898. & 2. & 0.75 \\
\hline 7 & 17 & 7 & 0 & 1 & 1875 & 750 & 4. & 1.19 \\
\hline 8 & 8 & 8 & 1 & 1 & 2246 & 898 & 5. & 1.46 \\
\hline 9 & 15 & 9 & 0 & 1 & 1875. & 750. & 4. & 1.26 \\
\hline 10 & 20 & 10 & 0 & 1 & 1875 & 750. & 4 & 0.69 \\
\hline 11 & 16 & 11 & 0 & 1 & 1875 & 750. & 4. & 1.28 \\
\hline 12 & 11 & 12 & -1 & 1 & 1875 & 500. & 4 & 0.84 \\
\hline 13 & 18 & 13 & 0 & 1 & 1875 & 750. & 4. & 0.94 \\
\hline 14 & 5 & 14 & 1 & 1 & 1503 & 601. & 5. & 1.30 \\
\hline 15 & 6 & 15 & 1 & 1 & 2246 & 601. & 5. & 1.20 \\
\hline
\end{tabular}

Table 6. Estimated Regression Coefficients for Roughness.

\begin{tabular}{|l|l|l|l|c|}
\hline \multicolumn{1}{|c|}{ Term } & Coef. & $\begin{array}{l}\text { SE } \\
\text { Coef. }\end{array}$ & T & P \\
\hline Constant & 1.18692 & 0.6572 & 1.806 & 0.101 \\
\hline Pressure & 0.07895 & 0.4360 & 0.181 & 0.860 \\
\hline Power & -0.10724 & 0.4360 & -0.246 & 0.811 \\
\hline Speed & -0.90223 & 0.4360 & -2.069 & 0.065 \\
\hline Pressure*Pressure & -0.30510 & 0.4244 & -0.719 & 0.489 \\
\hline Power*Power & -0.15308 & 0.4244 & -0.361 & 0.726 \\
\hline Speed*Speed & 0.96062 & 0.4244 & 2.263 & 0.047 \\
\hline Pressure*Power & 0.02375 & 0.5697 & 0.042 & 0.968 \\
\hline
\end{tabular}




\begin{tabular}{|c|c|c|c|c|}
\hline Pressure*Speed & -0.12125 & 0.5697 & -0.213 & 0.8 \\
\hline Power*Speed & -0.09875 & 0.5697 & -0.173 & 0.8 \\
\hline \multicolumn{5}{|c|}{$\mathrm{S}=1.61129 \quad \mathrm{PRESS}=194.375$} \\
\hline
\end{tabular}

\subsection{Interpreting the Results and Discussion}

Since the non-linear model is consider as a higher-order model, it will be needed to adequately model the response surface as well, and full the quadratic model. For the full quadratic model, p-value for lack of fit is 0.000 will be suggested for this model to adequately fits the data shown in Table 6 and Table 7 .

The results shown in Table 6 are the estimated regression coefficients for roughness to all the terms in the model. By using an orthogonal design, each effect is estimated independently. Therefore, the coefficients of linear terms are the same as in the linear model. The error term, $\mathrm{S}=1.61129$, is smaller because of reducing the variability accounted for by the error. For versus fits, the residuals do not appear to be randomly scattered about zero.

The analysis of variance for surface roughness in Table 7 summarizes the linear terms, the squared terms, and the interactions. The large $p$-values for the interactions $\mathrm{P}=0.994$ and the squared terms $\mathrm{P}=0.165$ suggests there is curvature in the surface roughness. Large $\mathrm{p}$-values of the pressure by power interaction $\mathrm{P}=$ 0.968 , pressure by speed interaction $\mathrm{P}=0.836$ and power by speed interaction $\mathrm{P}=0.866$. Squared $\mathrm{P}=0.489$, and power squared $\mathrm{P}=0.726$ and speed squared smallest $\mathrm{P}=$ 0.047 indicate that these effects are statistically significant. The p-value of 0.000 indicates that the factor of green colour is significant.

Table 7. Analysis of Variance for Roughness.

\begin{tabular}{|l|l|l|l|l|l|l|}
\hline Source & DF & $\begin{array}{c}\text { Seq } \\
\text { SS }\end{array}$ & $\begin{array}{c}\text { Adj } \\
\text { SS }\end{array}$ & $\begin{array}{l}\text { Adj } \\
\text { MS }\end{array}$ & F & P \\
\hline $\begin{array}{l}\text { Regress } \\
\text { ion }\end{array}$ & 9 & 27.8 & 27.8 & 3.09 & 1.19 & 0.39 \\
\hline Linear & 3 & 11.3 & 11.3 & 3.78 & 1.46 & 0.28 \\
\hline $\begin{array}{l}\text { Pressur } \\
\text { e }\end{array}$ & 1 & 0.08 & 0.08 & 0.08 & 0.03 & 0.86 \\
\hline Power & 1 & 0.15 & 0.15 & 0.15 & 0.06 & 0.81 \\
\hline Speed & 1 & 11.1 & 11.1 & 11.1 & 4.28 & 0.06 \\
\hline Square & 3 & 16.2 & 16.2 & 5.43 & 2.09 & 0.16 \\
\hline $\begin{array}{l}\text { Pressur } \\
\text { e* } \\
\text { Pressur } \\
\text { e }\end{array}$ & 1 & 2.09 & 1.34 & 1.34 & 0.52 & 0.48 \\
\hline $\begin{array}{l}\text { Power* } \\
\text { Power }\end{array}$ & 1 & 0.89 & 0.33 & 0.33 & 0.13 & 0.72 \\
\hline $\begin{array}{l}\text { Speed* } \\
\text { Speed }\end{array}$ & 1 & 13.2 & 13.2 & 13.2 & 5.12 & 0.04 \\
\hline $\begin{array}{l}\text { Interac } \\
\text { tion }\end{array}$ & 3 & 0.20 & 0.20 & 0.06 & 0.03 & 0.99 \\
\hline $\begin{array}{l}\text { Pressur } \\
\text { e* } \\
\text { Power }\end{array}$ & 1 & 0.00 & 0.00 & 0.00 & 0.00 & 0.96 \\
\hline $\begin{array}{l}\text { Pressur } \\
\text { e* } \\
\text { Speed }\end{array}$ & 1 & 0.11 & 0.11 & 0.11 & 0.05 & 0.83 \\
\hline $\begin{array}{l}\text { Power* } \\
\text { Speed }\end{array}$ & 1 & 0.07 & 0.07 & 0.07 & 0.03 & 0.86 \\
\hline
\end{tabular}

\begin{tabular}{|l|l|l|l|l|l|l|}
\hline $\begin{array}{l}\text { Residu } \\
\text { al } \\
\text { Error }\end{array}$ & 10 & 25.9 & 25.9 & 2.59 & & \\
\hline $\begin{array}{l}\text { Lack } \\
\text {-of-Fit }\end{array}$ & 5 & 25.5 & 25.5 & 5.11 & 63.8 & 0.00 \\
\hline $\begin{array}{l}\text { Pure } \\
\text { Error }\end{array}$ & 5 & 0.40 & 0.40 & 0.08 & & \\
\hline Total & 19 & 53.8 & & & & \\
\hline
\end{tabular}

Figure (5) is the contour plots which indicate that the highest roughness is obtained when pressure levels are low and power levels are high. This area appears at the upper left corner of the plot. The analysis for surface roughness $(\mathrm{Ra})$ was done by using the response surface regression as shown in Table 5 and Table 6.

Whereby; $\mathrm{P}$ - value is denoted the importance of the parameter having less than 0.05 is deemed significant the important factor if focused in this note here. It can be observed from the estimated regression coefficients for Ra that the (cutting speed * cutting speed) has the lowest $\mathrm{p}$ - value of 0.047 only. This indicates that this parameter has considerable effect on the surface roughness when the $\mathrm{p}$ - value is less than 0.05 . That's mean the model is fit and the defect in this model is not too significant. from the analysis of variance section, the linear regression has a smallest $\mathrm{p}$ - value with 0.047 , and that's means the empirical model is going to be a square model.

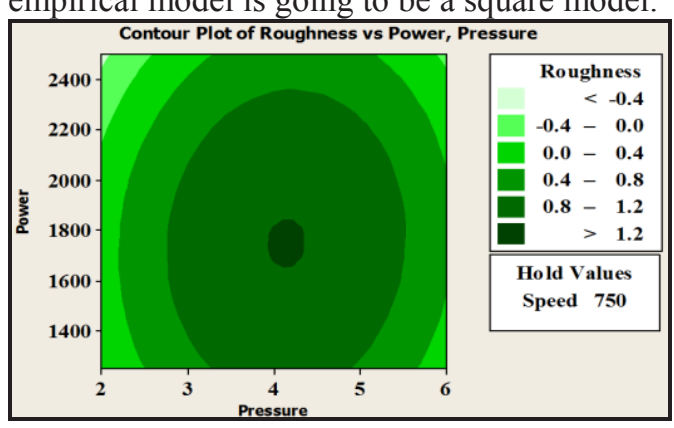

Figure 5. Contour Plot.

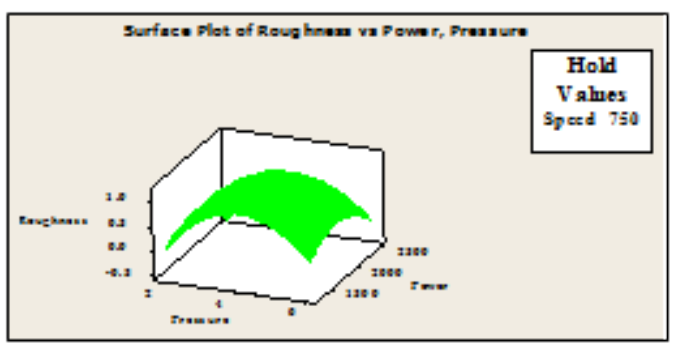

Figure 6. Surface Plot.

Contour plots in Figure (6) indicate that the highest yield is obtained when pressure levels are low and power levels are high. This area appears at the upper left corner of the plot. Surface plots in Figure (7) indicate that the highest yield is obtained when pressure levels are low and power levels are high. This area appears at the upper left corner of the plot. In addition, It's important to keep in mind that these plots should be based on a model equation, and the model is adequate before interpreting the plots 


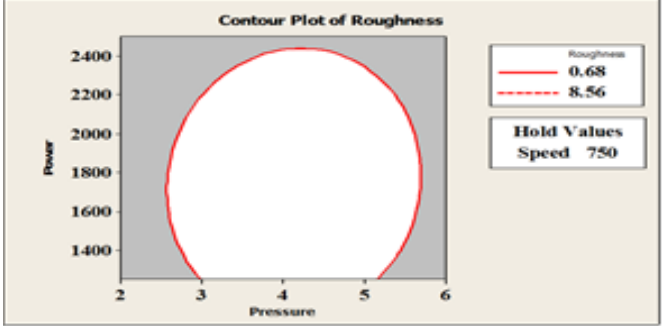

Figure 7. Contour of Roughness.

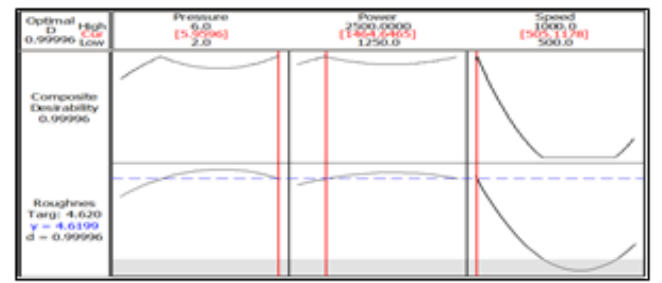

Figure 8. Surface Roughness Optimization.

In Figure (7), the white area in the mid square of the plot shows the range of pressure and power where the criteria for both response variables are satisfied. You may increase or decrease the holding value to see the range change. To understand the feasible region formed by the three factors, it's important to repeat the process to obtain plots for all pairs of factors.

\section{Response Optimization}

Table 8 shows the results surface roughness optimization

Table 8. Surface Roughness Optimization.

\begin{tabular}{|l|c|c|c|c|c|c|}
\hline $\begin{array}{l}\text { Roughn } \\
\text { ess }\end{array}$ & $\begin{array}{c}\text { Goal } \\
\text { Ga }\end{array}$ & $\begin{array}{c}\text { Targ } \\
\text { et }\end{array}$ & $\begin{array}{c}\text { Upp } \\
\text { er }\end{array}$ & $\begin{array}{c}\text { Weig } \\
\text { ht }\end{array}$ & $\begin{array}{c}\text { Impo } \\
\text { rt }\end{array}$ \\
\cline { 2 - 7 } & Target & 0.68 & 4.62 & 8.56 & 1 & 1 \\
\hline
\end{tabular}

As show in Figure (8), the individual desirability of both surface roughness and the variance in surface roughness is 0.99996; therefore the combined or composite desirability of these two variables is 0.99996 . To obtain this desirability, you would set the factor levels at the values shown under Global Solution. That is, pressure would be set at 5.9596, power at 1464.6465, and speed at 505.1178. Move the vertical bars to change the factory settings and see how the individual desirability of the responses and the composite desirability change. In Figure (8) you may want to see if you can reduce the speed which would save costs and still meet the product specifications.

\section{Conclusions}

The research findings suggest that RSM can be used to model the laser cutting process for stainless steel duplex 2205 materials. Three separate models in the form of polynomial equations were successfully developed to relate the relationships between machine, laser input process parameters (Co2 pressure, cutting speed, and power supply) and output responses (surface roughness).

The models were also qualitatively validated by justifying the behaviour of the output responses (roughness) with respect to variation of input variables, based on published work by researchers and practitioners in this field. This study also identified the significant parameters that influenced the cutting roughness through ANOVA analysis during the development of the models. Surface roughness was influenced by $\mathrm{Co} 2$ pressure and power supply, but cutting performance was influenced by speed. The ANOVA analysis also suggested that there was a significant interaction between the $\mathrm{Co} 2$ pressure and power supply which cannot be ignored and has not been reported in published journals. The ANOVA analysis indicated that the interaction between the pressure and power significantly influenced the resultant cutting roughness. The correlation study between cutting characteristics and the non-linear inclined suggested that the cutting performance correlated most significantly to the surface roughness with stainless steel type value. The study also suggested some correlation between cutting performance with percentage ratio of roughness measurement in stainless steel.

\section{References}

1. Choudhury, I. A., \& Shirley, SLaser cutting of polymeric materials: An experimental investigation. Optics \& Laser Technology, 42(3), 503-508. . (2010).

2. Eltawahni, H. A., Hagino, M., Benyounis, K. Y., Inoue, T., \& Olabi, A. G. Effect of CO2 laser cutting process parameters on edge quality and operating cost of AISI316L. 44(4), 1068-1082. (2012).

3. Madić, M., Radovanović, M., \& Nedić, B. Correlation between Surface Roughness Characteristics in CO2 Laser Cutting of Mild Steel. Tribology in Industry vol. 34, No. 4. (2012).

4. Samant, A. N., \& Dahotre, N. B. Laser machining of structural ceramics: a review. Journal of the European Ceramic Society, 29(6), 969-993. (2009).

5. Tulasiramarao, B., Srinivas, K., Effect of Processing Parameters on Surface Finish of the Components Processed By CNC Turning Machine. IJMEAR. Vol 04, Issue 01. (2013),

6. Dubey, A. K., \& Yadava, V. Laser beam machining: a review. International Journal of Machine Tools and Manufacture, 48(6), 609-628. (2008).

7. Samant, A. N., \& Dahotre, N. B. (2009). Laser machining of structural ceramics: a review. Journal of the European Ceramic Society, 29(6), 969-993

8. Ghany KA, Newish M. Cutting of $1.2 \mathrm{~mm}$ thick austenitic stainless steel sheet using pulsed and CWNd:YAG laser. Journal of Materials Processing Technology; 168:438-47. (2005).

9. Gok, A., Gologlu, C., Demirci, H. I., \& Kurt, M. Determination of Surface Qualities on Inclined Surface Machining with Acoustic Sound Pressure. Strojniški vestnik - Journal of Mechanical Engineering, 58(10), 587-597. (2012).

10. Eltawahni H. A., A. G. Olabi, and K. Y. Benyounis, 2011. "Investigating the CO2 laser cutting parameters of MDF wood composite material," Optics \& Laser Technology, vol. 43, no. 3, pp. 648659, Apr. (2011). 